\title{
Breast Fibrosarcoma
}

National Cancer Institute

\section{Source}

National Cancer Institute. Breast Fibrosarcoma. NCI Thesaurus. Code C5185.

A usually agg ressive malignant neoplasm arising from the breast. It is characterized by the presence of spindle-shaped fibroblasts and collagenous stroma formation in a herring bone growth pattern. 